\title{
Evaluasi Kondisi dan Kerusakan Perkerasan Lentur Dengan Metode Pavement Condition Index (Pci) \\ (Studi Kasus: Jalan Gunung Selatan Kota Tarakan Provinsi Kalimantan Utara)
}

\author{
Muhammad Djaya Bakri \\ Program Studi Teknik Sipil, Fakultas Teknik, Universitas Borneo Tarakan, \\ Jalan Amal Lama No. 01 Tarakan 77123 Indonesia \\ E-mail: jayabakri@gmail.com
}

Received 07 September 2019; Reviewed 10 September 2019; Accepted 21 November 2019 Journal Homepage: http://jurnal.borneo.ac.id/index.php/borneoengineering

\begin{abstract}
The Gunung Selatan Road is a road of secondary collector with the class of road is IIIB, has a width of 6.0 meters and a length of $4.109 \mathrm{~km}$, has an important role in driving the economy and connecting sub-districts in the north and west with sub-districts in the central and eastern parts of the city of Tarakan. The use of this road is directed to serve the transportation of construction materials which generally have a load to overloading which has the potential to cause damage to the road. This study aims to assess the condition of road pavement, using the method of the Pavement Conditition Index (PCI). Observation areas along the road segment are divided into road segments or sample units of observation with a width of 6.0 meters and a length of $50 \mathrm{~m}$, so that the size of each segment of $300 \mathrm{~m}^{2}$ is obtained, with a total of 40 road sample units. The types of damage found at the time of observation include: alligator crack, bleeding, block cracking, corrugation, depression, edge cracking, longitudinal/transverse cracking, patching and utility cut patching, pothole, and weathering/raveling. The average assessment results show the road is in criteria is very good condition with a value of PCI $=71$, but there is one observation that gives a criteria is poor, namely the sample unit at Sta. $1+350$ to $1+400$ with a PCI value of 29.5. This happened, at the time of observation the field condition was damaged and was being repaired.
\end{abstract}

Keywords: Pavement Condition Index (PCI), Identification, Assesment of Damage Condition

\begin{abstract}
Abstrak
Jalan Gunung Selatan merupakan jalan kolektor sekunder dengan kelas jalan IIIB, memiliki lebar 6,0 meter dan panjang 4,109 km, mempunyai peranan cukup penting dalam menggerakkan perekonomian dan menghubungkan wilayah kecamatan di bagian utara dan barat dengan kecamatan di bagian tengah dan timur kota Tarakan. Penggunaan jalan ini diarahkan untuk melayani angkutan material konstruksi yang pada umumnya memiliki muatan yang melebihi kapasitas jalan yang potensial menimbulkan kerusakan pada jalan. Penelitian ini bertujuan menilai kondisi perkerasan jalan, dengan menggunakan metode Pavement Conditition Index (PCI). Lokasi pengamatan sepanjang ruas jalan dibagi menjadi segmen jalan atau unit sampel pengamatan dengan lebar 6,0 meter dan panjang $50 \mathrm{~m}$, sehingga diperoleh ukuran masing-masing segmen $300 \mathrm{~m}^{2}$, dengan total sebanyak 40 unit sampel jalan. Jenis kerusakan yang ditemukan pada saat pengamatan antara lain yaitu: retak kulit buaya, kegemukan, retak kotak-kotak, keriting, amblas, retak samping jalan, retak memanjang/melintang, tambalan, lubang, dan pelepasan butir. Hasil penilaian secara rata-rata menunjukkan jalan dalam kondisi cukup baik (satisfactory) dengan nilai $P C I=71$, tetapi terdapat satu hasil pengamatan yang memberikan nilai sangat buruk (very poor) yaitu unit sampel pada Sta. $1+350 \mathrm{~s} / d$ 1+400 dengan nilai $P C I=29,5$. Hal ini terjadi, pada saat pengamatan kondisi lapangan mengalami kerusakan dan sedang dalam perbaikan.
\end{abstract}

Kata Kunci: Pavement Condition Index (PCI), Identifikasi, Penilaian Kondisi Kerusakan Jalan 


\section{Pendahuluan}

Jalan merupakan prasarana angkutan darat yang sangat penting dalam memperlancar distribusi jasa dan barang dalam kegiatan perekonomian, dan memperlancar konektifitas antar kawasan. Kondisi jalan yang baik akan meningkatkan mobilitas masyarakat dalam melakukan aktifitas perekonomian dan kegiatan sosial lainnya (Djalante, 2011). Jaringan jalan yang dilalui volume lalu lintas yang tinggi dan berulang-ulang, dapat menurunkan kualitas dari permukaan jalan tersebut, sehingga tidak nyaman dan tidak aman untuk dilalui.

Jalan Gunung Selatan di kota Tarakan Provinsi Kalimantan Utara mempunyai peranan cukup penting dalam menggerakkan perekonomian dan mendukung kegiatan sosial masyarakat. Jalan ini berfungsi sebagai jalan kolektor sekunder karena menghubungkan wilayah kecamatan di bagian utara dan barat dengan kecamatan di bagian tengah dan timur kota Tarakan seperti ditampilkan pada Gambar 1. Karena letaknya di pinggiran kota, sehingga Pemerintah Kota Tarakan mengarahkan penggunaan jalan tersebut untuk melayani angkutan material konstruksi yang pada umumnya memiliki muatan yang melebihi kapasitas jalan yang potensial menimbulkan kerusakan pada jalan.

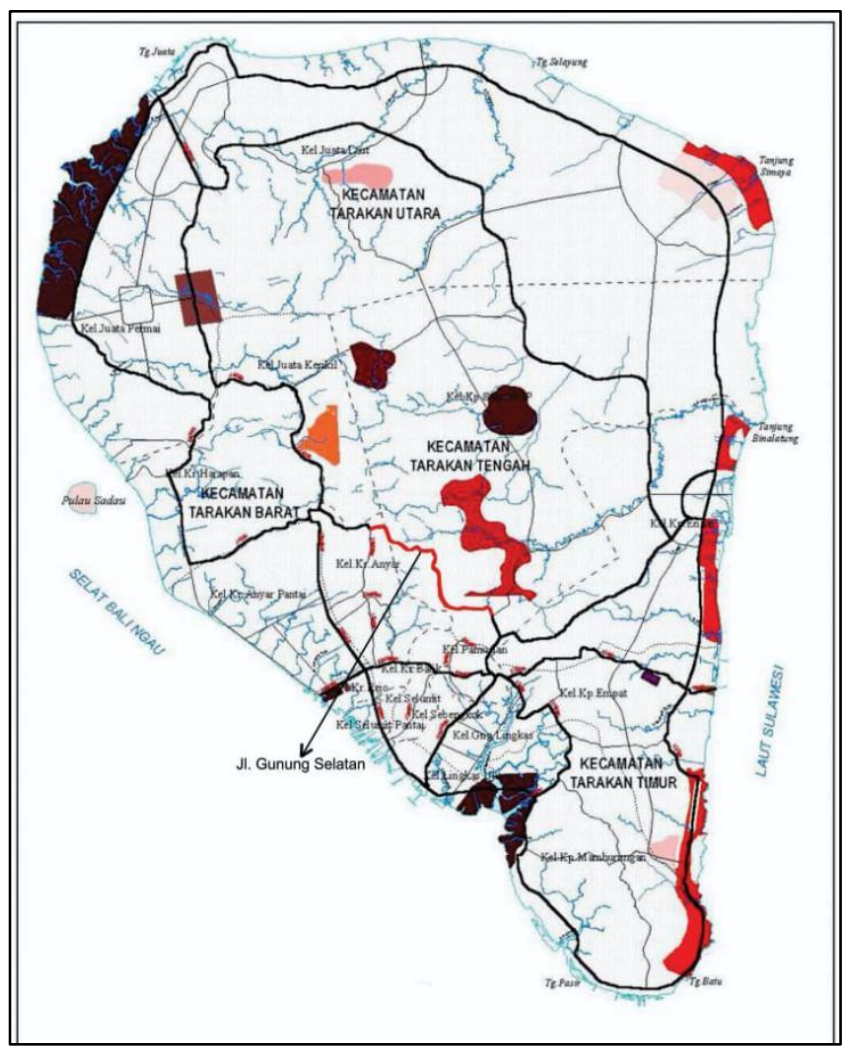

\section{Gambar 1. Lokasi Jalan Gunung Selatan Tarakan}

Untuk dapat menilai kondisi permukaan jalan yang mengalami kerusakan sebagai dasar untuk program perbaikan, Mubarak (2016) menganjurkan perlu menetapkan suatu metode yang memberikan acuan dalam melakukan identifikasi kerusakan, analisis terhadap kerusakan, mengklasifikasikan kondisi perkerasan dan memberikan solusi penanganan kerusakan tersebut. Identifikasi terhadap kerusakan, penentuan penyebab dan perbaikan yang tepat bersifat subyektif. Hal tersebut sering kali menimbulkan perbedaan pandangan mengenai persoalan yang sama dan setiap orang dapat mengambil solusi yang mungkin sangat berbeda. Oleh karena itu adalah sangat penting menyamakan persepsi tentang bagaimana bentuk penilaian terhadap kondisi jalan (road 
condition assessment) dan identifikasi kerusakan yang terjadi, penentuan penyebab serta akibat lebih lanjut.

Ada beberapa metode pendekatan yang dapat digunakan dalam penilaian kondisi jalan seperti metode Bina Marga, metode PCI (Pavement Condition Index), dan metode PDI (Pavement Distress Index). Metode $P C I$ lazim digunakan dalam penilaian kondisi jalan, karena dalam penggunaannya di lapangan tidak memerlukan peralatan khusus, hanya berbasis pengamatan visual dan pengukuran kerusakan di lapangan yang akan mendapatkan tipe kerusakan dan tingkat keparahan kerusakan (Shahin, 2005). Dalam studi evaluasi kondisi dan kerusakan jalan ini menggunakan metode PCI (Pavement Condition Index).

\section{Metode dan Studi Literatur}

\subsection{Jenis dan Fungsi Perkerasan Lentur}

Nawir dan Mansur (2017) menyebutkan bahwa konstruksi perkerasan lentur (flexible pavement), adalah perkerasan yang menggunakan aspal sebagai bahan pengikat dan lapisan-lapisan perkerasannya bersifat memikul dan menyebarkan beban lalu lintas ke tanah dasar. Adapun susunan dan fungsi setiap lapisan perkerasan lentur adalah sebagai berikut:

a. Lapis Permukaan (surface course)

Lapisan yang terletak paling atas, secara struktural berfungsi mendukung dan menyebarkan beban kendaraan yang diterima oleh perkerasan, baik beban vertikal maupun beban horizontal (gaya geser) ke lapisan-lapisan dibawahnya. Secara non struktural, berfungsi sebagai lapis kedap air, mencegah masuknya air ke dalam lapisan perkerasan yang ada di bawahnya, menyediakan permukaan yang tetap rata, agar kendaraan dapat berjalan dan memperoleh kenyamanan yang cukup, membentuk permukaan yang tidak licin, sehingga tersedia koefisien gerak (skid resistance) yang cukup untuk menjamin tersedianya keamanan lalu lintas, dan sebagai lapisan aus, yaitu lapis yang dapat aus yang selanjutnya dapat diganti lagi dengan yang baru.

b. Lapis Pondasi Atas (base course)

Lapisan perkerasan ini terletak di antara lapis pondasi bawah dan lapis permukaan, berfungsi sebagai bagian dari kontruksi perkerasan untuk mendukung lapisan diatasnya dan menyebar beban roda ke lapisan dibawahnya. Lapisan ini banyak menerima pembebanan yang berat dan yang paling menderita akibat muatan, oleh karena itu material yang digunakan harus berkualitas sangat tinggi dan pelaksanaan konstruksi harus dilaksanakan dengan cermat.

c. Lapis Pondasi Bawah (subbase course)

Lapisan perkerasan ini terletak di antara lapis pondasi atas dan tanah dasar (subgrade), berfungsi sebagai bagian dari kontruksi perkerasan untuk menyebarkan beban roda ke tanah dasar. Lapisan ini harus cukup kuat, mempunyai CBR $>20 \%$ dan Plastisitas Indeks (PI) $>10 \%$. Fungsi lainnya sebagai lapisan pertama dalam konstruksi perkerasan, dan sebagai lapisan peresapan diperlukan pemadatan optimum dalam pelaksanaannya sehingga dapat berfungsi dengan baik mencegah air tanah naik ke lapisan diatasnya.

d. Tanah Dasar (subgrade)

Lapisan ini merupakan permukaan dasar untuk perletakan konstruksi lapisan perkerasan. Lapisan tanah dasar ini bisa dibentuk dari permukaan tanah asli, permukaan tanah galian ataupun tanah tanah timbunan yang dipadatkan sampai tingkat kepadatan tertentu sehingga mempunyai daya dukung yang baik.

\subsection{Penyebab Kerusakan Jalan}

Sukirman (1999) menyebutkan bahwa kerusakan pada konstruksi perkerasan jalan dapat disebabkan hal sebagai berikut: 
a. Arus lalulintas, dapat berupa peningkatan dan reputasi beban.

b. Air, yang dapat berupa air hujan, sistem drainase yang tidak baik, naiknya air akibat kapilaritas.

c. Material konstruksi perkerasan, dalam hal ini disebabkan oleh sifat material itu sendiri atau dapat pula disebabkan oleh sistem pengelolaan bahan yang tidak baik.

d. Iklim, Indonesia beriklim tropis dimana suhu udara dan curah hujan umumnya tinggi, yang merupakan salah satu penyebab kerusakan jalan.

e. Kondisi tanah dasar yang tidak stabil, kemungkinan disebabkan oleh sistem pelaksanaan yang kurang baik, atau dapat juga disebabkan oleh sifat tanah yang memang jelek.

f. Proses pemadatan lapisan diatas tanah yang kurang baik.

\subsection{Metoda PCI (Pavement Condition Index)}

Shahin (2005) mengemukakan bahwa hal terpenting dalam sistem manajemen perkerasan adalah kemampuannya baik dalam menetapkan kondisi eksisting dari suatu ruas jalan maupun dalam memprediksi kondisi di masa yang akan datang. Metode PCI (Pavement Condition Index) yang dikembangkan oleh U.S. Army Corps of Engineers (Shahin, 2005) dapat digunakan untuk memprediksi kondisi jalan dengan sistem perangkingan dengan menyatakan kondisi perkerasan yang sesungguhnya dengan data yang dapat dipercaya dan obyektif. Penggunaan Metode PCI telah meluas di Amerika Serikat, dipergunakan dalam beberapa penilain kondisi perkerasan seperti perkerasan bandara, jalan dan tempat parkir. Shahin (2005) menyebutkan bahwa PCI (Pavement Condition Index) adalah tingkatan dari kondisi permukaan perkerasan dan ukurannya yang ditinjau dari fungsi daya guna yang mengacu pada kondisi dan kerusakan di permukaan perkerasan yang terjadi. Nilai PCI didasarkan pada hasil survei kondisi visual. Tipe kerusakan, tingkat keparahan kerusakan, dan ukurannya diidentifikasikan saat kondisi survei tersebut. $P C I$ dikembangkan untuk memberikan indeks dari integritas suatu perkerasan dan kondisi operasional permukaannya.

\subsection{Jenis Kerusakan Jalan}

Khusus untuk keperluan dalam perhitungan nilai kondisi jalan dengan menggunakan metode $P C I$, kerusakan jalan kontruksi flexible pavement dengan lapis permukaan aspal beton dibedakan dalam 19 jenis kerusakan. Jenis kerusakan terebut seperti disajikan pada Tabel 1.

\section{Tabel 1. Jenis Kerusakan Jalan Flexible Pavement Dengan Lapis Permukaan Aspal Beton}

\begin{tabular}{|c|c|c|}
\hline No. & Jenis Kerusakan & Deskripsi Jenis Kerusakan \\
\hline 1. & $\begin{array}{l}\text { Retak Kulit Buaya } \\
\text { (Aligator Cracking) }\end{array}$ & $\begin{array}{l}\text { Retak ini merupakan serangkaian retak memanjang paralel yang membentuk } \\
\text { banyak sisi menyerupai kulit buaya, dengan lebar celah lebih besar atau sama } \\
\text { dengan } 3 \mathrm{~mm} \text {. Retak ini disebabkan oleh kelelahan akibat beban lalu lintas yang } \\
\text { berulang-ulang }\end{array}$ \\
\hline 2. & Kegemukan (Bleeding) & $\begin{array}{l}\text { Kerusakan ini dapat dikenali dengan terlihatnya lapisan tipis aspal (tanpa } \\
\text { agregat) pada permukaan perkerasan dan jika pada kondisi terik matahari atau } \\
\text { pada lalu lintas yang berat, akan terlihat jejak bekas alur roda kendaraan yang } \\
\text { melewatinya. }\end{array}$ \\
\hline 3. & $\begin{array}{l}\text { Retak blok (Block } \\
\text { Cracking) }\end{array}$ & $\begin{array}{l}\text { Retak ini berbentuk blok-blok atau kotak-kotak besar yang saling bersambungan, } \\
\text { dengan ukuran sisi blok } 0,3 \text { sampai } 3 \text { m dan dapat membentuk sudut atau pojok } \\
\text { yang tajam. Retak ini terjadi umumnya pada lapisan tambahan (overlay), yang } \\
\text { menggambarkan pola retakan dibawahnya }\end{array}$ \\
\hline 4. & $\begin{array}{l}\text { Tonjolan dan Lengkungan } \\
\text { (Bump and Sags) }\end{array}$ & $\begin{array}{l}\text { Tonjolan adalah gerakan atau perpindahan keatas, bersifat lokal dan kecil dari } \\
\text { permukaan permukaan aspal. Pemindahan pada lapisan perkerasan ini } \\
\text { disebabkan perkerasan yang tidak stabil }\end{array}$ \\
\hline 5. & Keriting (Corrugation) & $\begin{array}{l}\text { Bentuk kerusakan ini berupa gelombang pada lapis permukaan, atau dapat } \\
\text { dikatakan alur yang arahnya melintang jalan, dan sering disebut juga sebagai } \\
\text { plastic movement. Kerusakan ini umumnya terjadi akibat pengereman kendaraan }\end{array}$ \\
\hline 6. & Amblas (Depression) & $\begin{array}{l}\text { Kerusakan yang terjadi berupa amblas atau turunnya permukaan lapisan } \\
\text { permukaan perkerasan pada lokasi tertentu (setempat) dengan atau tanpa retak. } \\
\text { Kedalaman kerusakan ini umumnya lebih dari } 2 \mathrm{~cm} \text { dan akan menampung atau } \\
\text { meresapkan air }\end{array}$ \\
\hline
\end{tabular}


Lanjutan Tabel 1.

\begin{tabular}{|c|c|c|}
\hline No. & Jenis Kerusakan & Deskripsi Jenis Kerusakan \\
\hline 7. & $\begin{array}{l}\text { Retak Tepi Jalan (Edge } \\
\text { Cracking) }\end{array}$ & $\begin{array}{l}\text { Retak tepi biasanya terjadi sejajar dengan tepi perkerasan dan berjarak sekitar } \\
0,3-0,5 \mathrm{~m} \text { dari tepi luar atau pinggir perkerasan. Retak ini biasanya disebabkan } \\
\text { oleh beban lalu lintas atau cuaca yang memperlemah pondasi atas maupun } \\
\text { pondasi bawah yang dekat dengan pinggir perkerasan }\end{array}$ \\
\hline 8. & $\begin{array}{l}\text { Retak Refleksi Sambungan } \\
\text { (Joint Reflection }\end{array}$ & $\begin{array}{l}\text { Kerusakan ini umumnya terjadi pada perkerasan aspal yang telah dihamparkan } \\
\text { di atas perkerasan beton semen. Retak terjadi pada lapis tambahan (overlay) } \\
\text { aspal yang mencerminkan pola retak dalam perkerasan beton lama yang } \\
\text { berbeda dibawahnya }\end{array}$ \\
\hline 9. & $\begin{array}{l}\text { Penurunan Bahu Jalan } \\
\text { (Lane/Shoulder Drop-Off) }\end{array}$ & $\begin{array}{l}\text { Bentuk kerusakan ini terjadi akibat terdapatnya beda ketinggian antara } \\
\text { permukaan perkerasan dengan permukaan bahu atau tanah sekitarnya, dimana } \\
\text { permukaan bahu jalan lebih rendah terhadap permukaan perkerasan }\end{array}$ \\
\hline 10. & $\begin{array}{l}\text { Retak Memanjang / } \\
\text { Melintang (Longitudinal } \\
\text { and Transverse Cracking) }\end{array}$ & $\begin{array}{l}\text { Retak berbentuk memanjang perkerasan jalan, dapat terjadi dalam bentuk } \\
\text { tunggal atau berderet yang sejajar dan kadang-kadang sedikit bercabang. Retak } \\
\text { melintang merupakan retak tunggal (tidak bersambungan satu sama lain) yang } \\
\text { melintang perkerasan }\end{array}$ \\
\hline 11. & $\begin{array}{l}\text { Tambalan dan Galian } \\
\text { Utilitas (Patching and } \\
\text { Utility Cut Patching) }\end{array}$ & $\begin{array}{l}\text { Tambalan adalah penutupan suatu bidang pada perkerasan dengan tujuan untuk } \\
\text { mengembalikan perkerasan yang rusak dengan material yang baru untuk } \\
\text { memperbaiki perkerasan yang ada }\end{array}$ \\
\hline 12. & $\begin{array}{l}\text { Pengausan Agregat } \\
\text { (Polished Aggregate) }\end{array}$ & $\begin{array}{l}\text { Kerusakan ini disebabkan oleh penerapan lalu lintas yang berulang-ulang } \\
\text { dimana agregat pada perkerasan menjadi licin dan perekatan dengan } \\
\text { permukaan roda pada tekstur perkerasan yang mendistribusikannya tidak } \\
\text { sempurna }\end{array}$ \\
\hline 13 & Lubang (Potholes) & $\begin{array}{l}\text { Kerusakan berbentuk lubang kecil atau mangkuk yang biasanya berdiameter } \\
\text { kurang dari } 0,9 \mathrm{~m} \text {, dapat atau tidak berhubungan dengan permukaan lainnya. } \\
\text { Lubang biasanya terjadi akibat galian utilitas atau tambalan di area perkerasan } \\
\text { yang telah ada. }\end{array}$ \\
\hline 14 & $\begin{array}{l}\text { Persilangan Jalan Rel } \\
\text { (Railroad Crossings) }\end{array}$ & $\begin{array}{l}\text { Kerusakan pada persilangan jalan rel dan jalan raya dapat terjadi berupa } \\
\text { amblas dan tonjolan di sekitar atau antara lintasan rel yang disebabkan oleh } \\
\text { perbedaan karakteristik bahan }\end{array}$ \\
\hline 15 & Alur (Rutting) & $\begin{array}{l}\text { Istilah lain yang digunakan untuk menyebutkan jenis kerusakan ini adalah } \\
\text { longitudinal ruts, atau channel/rutting. Bentuk kerusakan ini terjadi pada } \\
\text { lintasan roda sejajar dengan as jalan dan berbentuk alur }\end{array}$ \\
\hline 16 & Sungkur (Shoving) & $\begin{array}{l}\text { Sungkur adalah perpindahan permanen secara lokal dan memanjang dari } \\
\text { permukaan perkerasan yang disebabkan oleh beban lalulintas. }\end{array}$ \\
\hline 17 & $\begin{array}{l}\text { Retak Slip (Slippage } \\
\text { Cracking) }\end{array}$ & $\begin{array}{l}\text { Retak slip berbentuk seperti bulan sabit atau setengah bulan yang disebabkan } \\
\text { lapisan perkerasan terdorong atau meluncur merusak bentuk lapisan perkerasan } \\
\text { akibat gaya-gaya horizontal yang berasal dari kendaraan. }\end{array}$ \\
\hline 18 & Pengembangan (Swell) & $\begin{array}{l}\text { Pengembangan ini mempunyai ciri menonjol keluar sepanjang lapisan } \\
\text { perkerasan yang berangsur-ansur mengombak kira-kira panjangnya } 3 \mathrm{~m}\end{array}$ \\
\hline 19 & $\begin{array}{l}\text { Pelapukan dan Pelepasan } \\
\text { Butir (Wathering and } \\
\text { Ravelling) }\end{array}$ & $\begin{array}{l}\text { Kerusakan ini menunjukkan salah satu pada aspal pengikat tidak kuat untuk } \\
\text { menahan gaya dorong roda kendaraan atau menunjukkan kualitas campuran } \\
\text { yang jelek. }\end{array}$ \\
\hline
\end{tabular}

Sumber: Shahin (2005), Mubarak (2016)

\subsection{Prosedur Analisis Data dengan Metode PCI}

Penilaian kondisi perkerasan dengan metode $P C I$, diawali dengan pembagian unit sampel yang akan ditinjau jenis kerusakan dan penyebabnya, tingkat kerusakan, dan jumlah kerusakan. Kemudian mengidentifikasi kerusakan, menentukan nilai $P C I$ hingga penilaian kondisi perkerasan,

\subsubsection{Penentuan Unit Sampel}

Shahin (2005) memberikan petunjuk untuk identifikasi kerusakan jalan dengan metode $P C I$, terlebih dahulu membagi panjang ruas jalan yang akan ditinjau dalam beberapa unit sampel. Untuk jalan dengan permukaan aspal (termasuk aspal diatas perkerasan beton) dan jalan tanpa perkerasan, unit sampel didefinisikan sebagai luasan sekitar $2.500 \pm 1.000$ sq.ft $\left(233 \pm 93 \mathrm{~m}^{2}\right)$. Ukuran unit 
sampel sebaiknya mendekati nilai rata-rata yang direkomendasikan agar hasilnya akurat. Dari nilai tersebut dapat ditentukan jumlah total sampel $(\mathrm{N})$ yang ada pada area yang akan ditinjau. Jumlah sampel minimum yang harus ditinjau (n) dihitung dengan rumus sebagai berikut (Shahin, 2005):

$$
n=\frac{N s^{2}}{\frac{e^{2}}{4}(N-1)+s^{2}}
$$

dimana:

$\mathrm{N}$ = jumlah total unit sampel dalam suatu bagian perkerasan

$\mathrm{e} \quad=$ kesalahan yang diizinkan dalam estimasi dari bagian $P C I(\mathrm{e}=5)$

$\mathrm{s}=$ standar deviasi dari PCI antara unit sampel di dalam bagiannya (untuk perkerasan dengan permukaan aspal, $\mathrm{s}=10$ )

Setelah diperoleh jumlah minimum dari unit sampel, kemudian ditentukan jarak interval tiap sampel yang ditinjau, dihitung dengan persamaan sebagai berikut (Shahin, 2005):

$$
i=\frac{N}{n}
$$

dimana:

$\mathrm{i} \quad=$ interval jarak unit-unit sampel

$\mathrm{N}=$ jumlah total unit sampel dalam suatu bagian perkerasan

$\mathrm{n} \quad=$ jumlah unit sampel minimum

Penentuan jumlah unit sampel juga mempertimbangkan tujuan survey, karena dengan keterbatasan sumber daya mengakibatkan tidak seluruh unit sampel diperiksa. Oleh sebab itu diberikan alternatif jumlah sampel yang akan ditinjau berdasarkan jumlah sampel total (Shahin, 2005). Jumlah sampel yang harus ditinjau berdasarkan alternatif tersebut seperti disajikan pada Tabel 2.

Tabel 2. Rekomendasi Jumlah Sampel Survei PCI

\begin{tabular}{cc}
\hline Jumlah Unit Sampel & Unit Sampel Yang Disurvey \\
\hline \hline 1 sampai dengan 5 unit sampel & 1 unit sampel \\
6 sampai dengan 10 unit sampel & 2 unit sampel \\
11 sampai dengan 15 unit sampel & 3 unit sampel \\
16 sampai dengan 40 unit sampel & 4 unit sampel \\
lebih dari 40 unit sampel & $10 \%$ dari jumlah total unit sampel \\
\hline
\end{tabular}

Sumber: Shahin (2005)

\subsubsection{Identifikasi Kerusakan}

Beberapa penelitian sebelumnya, seperti Shahin (2005), Djalante (2011), Mubarak (2016), dan Widianto (2017), menyebutkan bahwa dalam mengevaluasi kerusakan jalan perlu ditentukan: jenis kerusakan (distress type) dan penyebabnya, tingkat keparahan kerusakan (distress severity), dan jumlah atau kerapatan kerusakan (distress amount).

Menurut Manual Pemeliharaan Jalan Nomor: 03/MN/B/1983 yang dikeluarkan oleh Direktorat Jenderal Bina Marga Departemen Pekerjaan Umum, jenis kerusakan jalan (distress type) dapat dibedakan atas: retak (cracking), distorsi (distortion), cacat permukaan (disintegration), pengausan (polished aggregate), kegemukan (bleeding or flushing), dan penurunan pada bekas penanaman utilitas (utility cut depression). Kemudian diukur tingkat kerusakan jalan (distress severity) seperti rendah (low), sedang (medium), dan tinggi (high). 


\subsubsection{Menghitung Kerapatan (Density).}

Kerapatan (density) adalah persentase luas atau panjang total dari jenis kerusakan terhadap luas atau panjang total bagian jalan yang diukur dalam satuan $\mathrm{ft}^{2}$ atau $\mathrm{m}^{2}$. Nilai density dihitung dengan persamaan sebagai berikut (Shahin, 2005):

$$
\text { Density }=\frac{A_{d}}{A_{s}} \times 100 \%
$$

atau

$$
\text { Density }=\frac{L_{d}}{A_{s}} x 100 \%
$$

dimana:

$\mathrm{A}_{\mathrm{d}}=$ luas total dari jenis kerusakan untuk tiap tingkat keparahan kerusakan $\left(\mathrm{ft}^{2}\right.$ atau $\left.\mathrm{m}^{2}\right)$.

$A_{s}=$ luas total unit sampel $\left(\mathrm{ft}^{2}\right.$ atau $\left.\mathrm{m}^{2}\right)$.

$\mathrm{L}_{\mathrm{d}}=$ panjang total jenis kerusakan untuk tiap tingkat keparahan kerusakan (ft atau m).

Persamaan 3 dan Persamaan 4 digunakan untuk kerusakan yang bisa diukur, misalnya retak pinggir, retak memanjang, melintang, dan penurunan bahu jalan. Untuk kerusakan tertentu seperti lubang, maka dihitung dengan persamaan sebagai berikut (Shahin, 2005):

$$
\text { Density }=\frac{\text { jumlah lub ang }}{A_{s}} \times 100 \%
$$

\subsubsection{Menentukan Nilai Pengurang (Deduct Value, DV).}

Nilai pengurang (Deduct Value) adalah suatu nilai pengurang untuk setiap jenis kerusakan yang diperoleh dari kurva hubungan antara kerapatan (density) dan tingkat keperahan (severity level) kerusakan. Pada Gambar 2 ditunjukkan kurve hubungan density dan deduct value, dimana grafik tersebut untuk menin kerusakan jenis gelombang (corrugation).

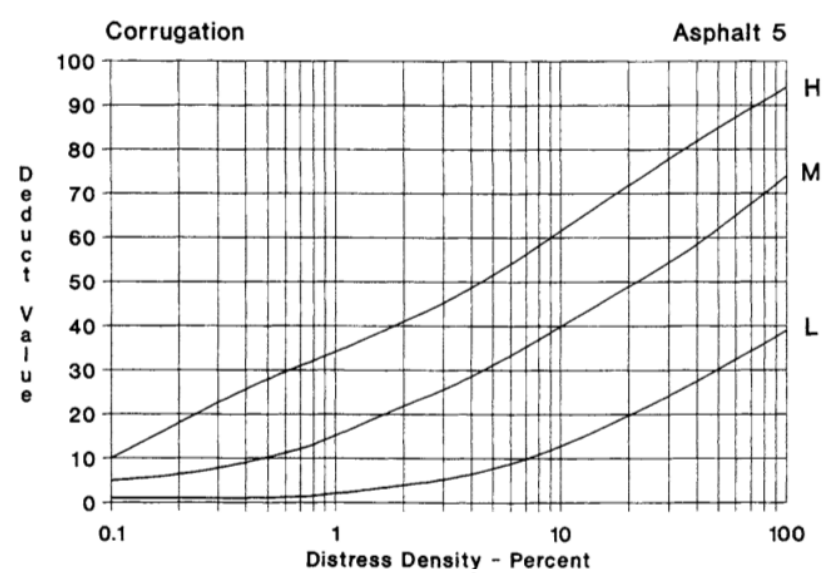

Gambar 2. Grafik Deduct Value untuk Corrugation Crack (Sumber: Shahin, 2005)

\subsubsection{Menghitung Nilai Allowable Number of Deduct (m).}

Dari hasil plotting pada masing-masing grafik hubungan antara Density dengan Deduct Value sesuai jenis kerusakan jalan, jika diperoleh hanya satu $D V$ yang $>5$ untuk lapangan terbang dan jalan tanah, atau > 2 untuk jalan permukaan aspal, maka Total Deduct Value (TDP) digunakan 
sebagai Corrected Deduct Value (CDV), jika tidak maka dilanjutkan menghitung nilai $C D V$ nya, dengan menghitung nilai izin jumlah deduct atau allowable number of deduct $(m)$. Nilai $m$ adalah maksimum $D V$ setiap jenis perkerasan yang diizinkan untuk diperhitungkan dalam penilaian kondisi perkerasan. Nilai $m$ ini dipengaruhi oleh $D V$ terbesar dalam suatu unit sampel. Nilai $m$ untuk perkerasan jalan dengan permukaan aspal dihitung dengan rumus sebagai berikut (Shahin, 2005):

$$
m_{i}=1+\left(\frac{9}{98}\right)\left(100-H D V_{i}\right)
$$

dimana:

$\mathrm{M} \quad=$ allowable number of deduct setiap unit sampel

$\mathrm{HDV}_{\mathrm{i}} \quad=$ highest deduct value, yaitu deduct value terbesar pada setiap unit sampel

\subsubsection{Menghitung Nilai Total Deduct Value (TDP) dan Corrected Deduct Value (CDV).}

Seluruh $D V$ yang telah didapatkan kemudian dijumlahkan sehingga didapat Total Deduct Value $(T D V)$. Dari data $D V$ dilihat berapa banyak yang memiliki nilai diatas 2 , yang nantinya disebut sebagai q. Nilai q tersebut nantinya dipasangkan dengan $T D V$, sehingga diperoleh Corrected Deduct Value $(C D V)$. CDV diperoleh dari kurva hubungan antara TDV dengan CDV dengan pemilihan lengkung grafik sesuai dengan jumlah nilai individual deduct value yang mempunyai nilai lebih besar dari 2 (Shahin, 2005). Grafik untuk menentukan nilai $C D V$ pada jalan dengan permukaan aspal seperti ditampilkan pada Gambar 3.

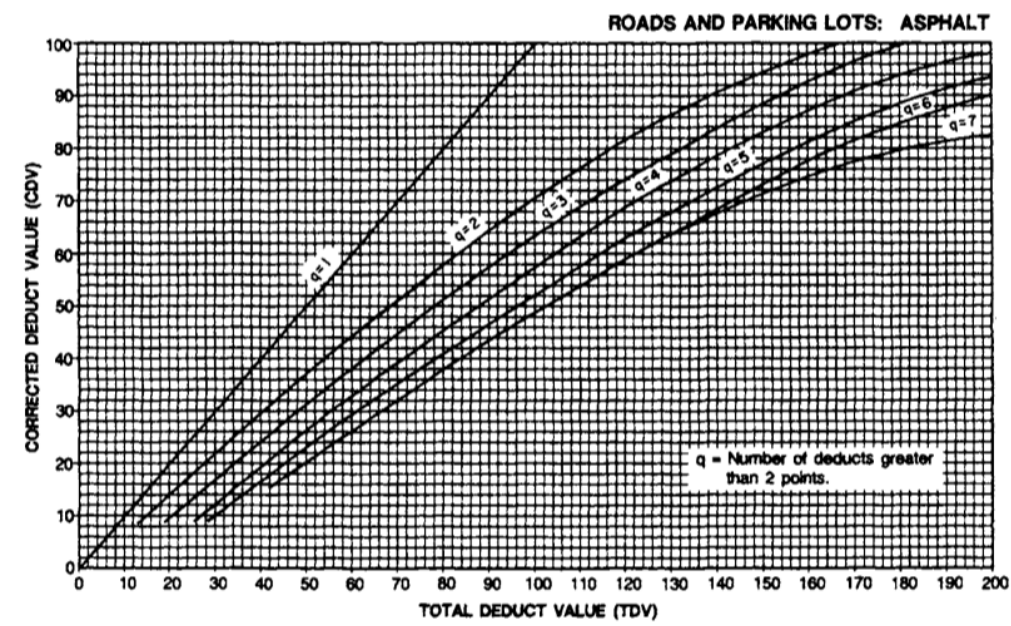

Gambar 3. Grafik Hubungan Antara $C D V$ dengan $T D V$ (Sumber: Shahin, 2005)

\subsubsection{Menentukan Nilai $P C I$.}

Shahin (2005) menjelaskan bahwa jika nilai $C D V$ telah diketahui, maka nilai $P C I$ untuk tiap unit sampel dapat dihitung dengan rumus sebagai berikut:

$$
P C I_{s}=100-C V D
$$

dimana:

$\mathrm{PCI}_{\mathrm{s}}=$ pavement condition index untuk tiap unit

$\mathrm{CVD} \quad=$ corrected deduct value untuk tiap unit 
Untuk menentukan nilai PCI secara keseluruhan pada ruas jalan tertentu dihitung dengan rumus sebagai berikut (Shahin, 2005):

$$
P C I_{f}=\sum \frac{P C I_{s}}{N}
$$

dimana:

$\mathrm{PCI}_{\mathrm{f}}=$ nilai pavement condition index rata-rata sampel unit dalam satu ruas jalan

$\mathrm{PCI}_{\mathrm{s}} \quad=$ nilai pavement condition index dalam satu ruas jalan

$\mathrm{N} \quad=$ jumlah sampel unit yang di survey

\subsubsection{Menentukan Kondisi Perkerasan}

Hitungan PCI didasarkan pada nilai pengurang DV yang besar nilainya mulai 0 sampai 100. Nilai pengurang ini menunjukkan pengaruh setiap kerusakan pada kondisi atau kinerja perkerasan. Nilai pengurang 0 mengindikasikan bahwa kerusakan tidak mempunyai pengaruh buruk pada kinerja perkerasan, sebaliknya nilai 100 menunjukkan kerusakan serius pada perkerasan jalan. Nilai PCI yang diperoleh kemudian digunakan untuk penilaian kondisi perkerasan. Pada Gambar 4 ditampilkan hubungan nilai PCI dengan kondisi perkerasan.

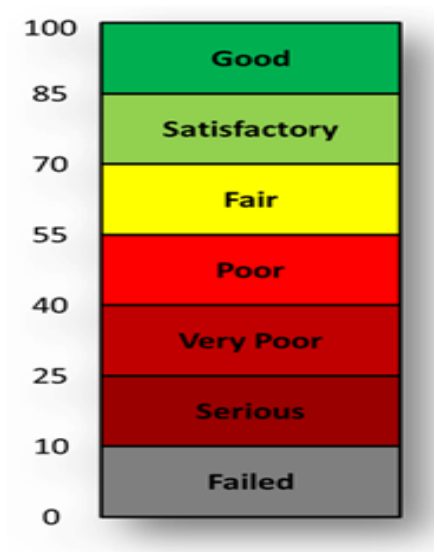

Gambar 4. Hubungan antara nilai PCI dengan kondisi Perkerasan (Sumber: Shahin, 2005)

Shahin (2005) mengemukakan nilai PCI tersebut dibagi dalam enam kriteria mulai dari kriteria sempurna (excellent) dengan rentang nilai 85-100, sangat baik (very good): 70-85, baik (good): 5570, cukup (fair): 40-55, jelek (poor): 25-40, sangat jelek (very poor): 10-25, dan gagal (failed): 010.

\section{Hasil dan Pembahasan}

\subsection{Menentukan Jumlah Unit Sampel}

Unit sampel adalah bagian atau seksi dari suatu perkerasan yang didefinisikan hanya untuk keperluaan pemeriksaan (Shahin, 2005). Unit sampel dibagi dalam beberapa unit, hal ini dilakukan untuk mempermudah dalam pelaksanaan pemeriksaan lapangan, perhitungan dan pengolahan data.

Dinas Perhubungan Kota Tarakan menyajikan dalam Tarakan Dalam Angka Tahun 2019 bahwa ruas jalan Gunung Selatan merupakan jalan kolektor sekunder dengan kelas jalan IIIB dan memiliki lebar 6,0 meter dan panjang 4,109 km. Jalan ini memiliki type 2/2 UD, setiap hari melayani sebesar 600-700 kendaraan/hari. Survey visual kondisi perkerasan jalan dilakukan mulai titik awal atau stasioning 0+000 dimulai dari persimpang Jalan Bhayangkara dan posisi stasioning 
akhir 4+100 di ujung Jalan Pepabri. Agar dalam penelitian ini diperoleh hasil penilaian kerusakan jalan yang memadai, maka ruas jalan yang ditinjau ditetapkan sepanjang 4,0 km dibagi menjadi 4 bagian penggal jalan, setiap penggal jalan sepanjang $1,0 \mathrm{~km}$. Ukuran unit sampel ditetapkan mendekati ukuran rekomendasi, dalam penelitian ini diambil ukuran lebar jalan 6,0 meter (19,69ft) dan panjang $50 \mathrm{~m}(164,04 \mathrm{ft})$ setiap segmen, sehingga diperoleh total segmen sebanyak 20 unit setiap penggal jalan dengan ukuran luasan masing-masing segmen $300 \mathrm{~m}^{2}$ (3.230 ft.sq).

Berdasarkan Persamaan 1, maka jumlah minimum unit sampel setiap penggal jalan yang ditinjau diperoleh sebanyak:

$$
n=\frac{N s^{2}}{\frac{e^{2}}{4}(N-1)+s^{2}}=\frac{20 \times 10^{2}}{\frac{5^{2}}{4}(20-1)+10^{2}}=9,14 \approx 10 \text { unit sampel }
$$

\subsection{Pemilihan Unit Sampel}

Pemilihan unit sampel merupakan interval yang dilakukan untuk pengambilan sampel secara acak, dihitung dengan Persamaan 2 dengan hasil sebagai berikut:

$$
i=\frac{N}{n}=\frac{20}{10}=2
$$

Jadi pemilihan unit sampel dilakukan setiap 2 interval seperti disajikan pada Gambar 5. dengan unit sampel yang ditinjau sebanyak 10 segmen setiap penggal jalan.

\begin{tabular}{|c|c|c|c|c|c|c|}
\hline 1 & 2 & 3 & 4 & 5 & 6 & 7 \\
\hline
\end{tabular}

\begin{tabular}{|c|c|c|c|c|c|c|}
\hline 8 & 9 & 10 & 11 & 12 & 13 & 14 \\
\hline
\end{tabular}

\begin{tabular}{|c|c|c|c|c|c|}
\hline 15 & 16 & 17 & 18 & 19 & 20 \\
\hline
\end{tabular}

\section{Gambar 5. Pembagian Potongan Unit Sampel Untuk Masing-Masing Penggal Jalan}

Menurut Shahin (2005) pengambilan unit sampel secara acak seperti ini mengandung kelemahan, karena bisa saja unit sampel yang terpilih adalah unit sampel dalam kondisi baik dan bisa saja terdapat unit sampel dalam kondisi buruk tidak terpilih dalam peninjauan. Untuk mengatasi hal tersebut, Shahin (2005) merekomendasikan untuk memasukkan unit sampel tambahan dalam peninjauan.

\subsection{Hasil Pengukuran Setiap Jenis Kerusakan dan Perhitungan Deduct Value}

Pengukuran untuk setiap jenis kerusakan dilakukan pada 10 sampel yang telah dipilih secara acak sepanjang penggal jalan atau sebanyak 40 sampel sepnajang ruas jalan. Dari hasil pengukuran dapat dihitung masing-masing Density, kemudian hasilnya diplotkan pada grafik hubungan antara Distress Density dengan Deduct Value untuk masing-masing type kerusakan. Contoh ploting hasil perhitungan Density yang dihubungkan dengan Deduct Value ditampilkan pada Gambar 6. Contoh hasil pengukuran setiap jenis kerusakan, perhitungan Density dan Deduct Value mewakili empat penggal jalan ditampilkan pada Tabel 3 sampai dengan Tabel 6. 


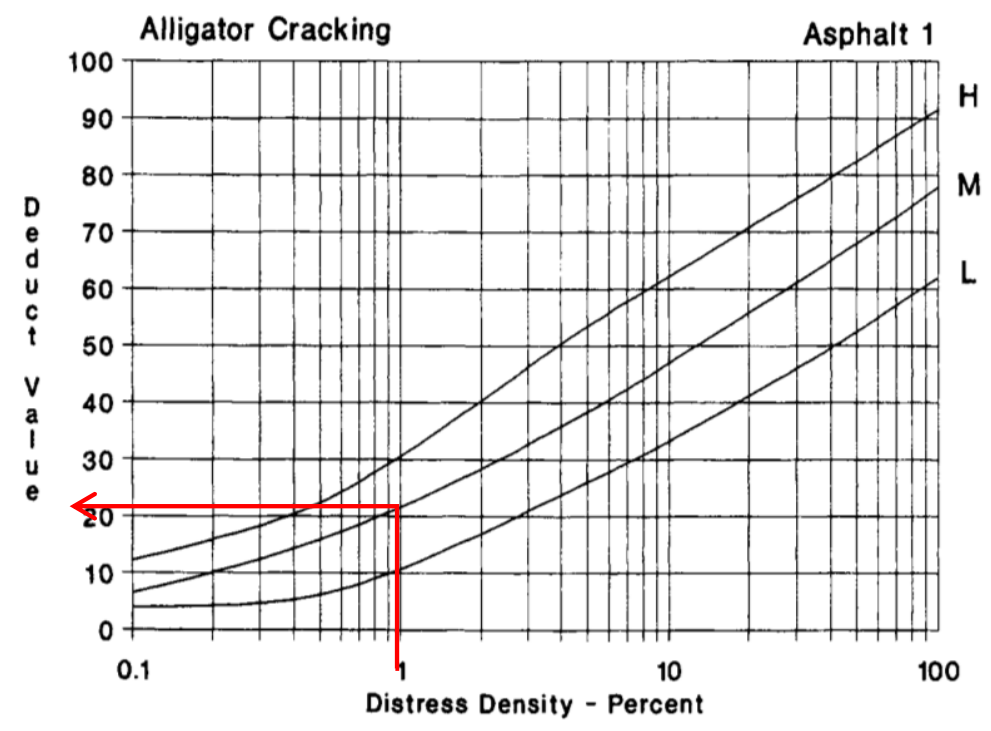

Gambar 6. Penentuan Nilai DV Pada Jenis Kerusakan Retak Kulit Buaya (Alligator Crack)

Tabel 3. Hasil Pengukuran Kondisi Kerusakan dan Perhitungan DV Sta. 0+150 s/d 0+200

\begin{tabular}{|c|c|c|c|c|c|}
\hline No. & Jenis Kerusakan & $\begin{array}{c}\text { Tingkat Keparahan } \\
\text { Kerusakan }\end{array}$ & $\begin{array}{c}\text { Total } \\
\text { Kerusakan }\end{array}$ & Density (\%) & Deduct Value \\
\hline 1 & Retak Kulit Buaya $\left(\mathrm{m}^{2}\right)$ & Medium & 2,88 & 0,96 & 21 \\
\hline 2 & Keriting $\left(\mathrm{m}^{2}\right)$ & Low & 2,16 & 0,72 & 1 \\
\hline 3 & Retak Samping Jalan (m) & Low & 12,4 & 4,13 & 3 \\
\hline 4 & Tambalan $\left(\mathrm{m}^{2}\right)$ & Medium & 22,32 & 7,44 & 28 \\
\hline 5 & Pelepasan Butir $\left(\mathrm{m}^{2}\right)$ & Medium & 8,4 & 2,80 & 11 \\
\hline
\end{tabular}

Tabel 4. Hasil Pengukuran Kondisi Kerusakan dan Perhitungan DV Sta. 1+350 s/d 1+400

\begin{tabular}{cccccc}
\hline No. & Jenis Kerusakan & $\begin{array}{c}\text { Tingkat Keparahan } \\
\text { Kerusakan }\end{array}$ & $\begin{array}{c}\text { Total } \\
\text { Kerusakan }\end{array}$ & Density (\%) & Deduct Value \\
\hline \hline 1 & Retak Kotak-Kotak $\left(\mathrm{m}^{2}\right)$ & Medium & 2.43 & 0,85 & 2 \\
2 & Amblas $\left(\mathrm{m}^{2}\right)$ & Medium & 8,16 & 2,72 & 13 \\
3 & Retak Memanjang/ & Medium & 4,5 & 1,50 & 28 \\
4 & Melintang (m) & Low & 12,4 & 4,13 & 3 \\
\hline
\end{tabular}

Tabel 5. Hasil Pengukuran Kondisi Kerusakan dan Perhitungan DV Sta. 2+450 s/d 2+500

\begin{tabular}{cccccc}
\hline No. & Jenis Kerusakan & $\begin{array}{c}\text { Tingkat Keparahan } \\
\text { Kerusakan }\end{array}$ & $\begin{array}{c}\text { Total } \\
\text { Kerusakan }\end{array}$ & Density (\%) & Deduct Value \\
\hline \hline 1 & Retak Kulit Buaya $\left(\mathrm{m}^{2}\right)$ & Low & 9,02 & 3,01 & 20 \\
2 & Retak Kotak-Kotak $\left(\mathrm{m}^{2}\right)$ & Low & 4,42 & 1,47 & 1 \\
3 & Keriting $\left(\mathrm{m}^{2}\right)$ & Low & 6,9 & 2,3 & 5 \\
4 & Amblas $\left(\mathrm{m}^{2}\right)$ & Low & 2,52 & 0,84 & 5 \\
5 & Retak Samping Jalan $(\mathrm{m})$ & Medium & 3,1 & 1,03 & 2 \\
6 & Tambalan $\left(\mathrm{m}^{2}\right)$ & Low & 2.64 & 0,88 & 21 \\
\hline
\end{tabular}

Tabel 6. Hasil Pengukuran Kondisi Kerusakan dan Perhitungan DV Sta. 3+250 s/d 3+300)

\begin{tabular}{cccccc}
\hline No. & Jenis Kerusakan & $\begin{array}{c}\text { Tingkat Keparahan } \\
\text { Kerusakan }\end{array}$ & $\begin{array}{c}\text { Total } \\
\text { Kerusakan }\end{array}$ & Density (\%) & Deduct Value \\
\hline \hline 1 & Retak Kulit Buaya $\left(\mathrm{m}^{2}\right)$ & Low & 7,38 & 2,46 & 19 \\
2 & Kegemukan $\left(\mathrm{m}^{2}\right)$ & Medium & 7,49 & 2,48 & 6 \\
3 & Retak Kotak-Kotak $\left(\mathrm{m}^{2}\right)$ & Low & 12,18 & 4,06 & 4 \\
4 & Retak Memanjang/ & Medium & 4,2 & 1,4 & 4 \\
5 & Melintang $(\mathrm{m})$ & Low & 4,08 & 1,36 & 4 \\
\hline
\end{tabular}




\subsection{Menghitung Allowable Maximum Deduct Value (m)}

Hasil plotting pada masing-masing grafik kerusakan jalan untuk menentukan Deduct Value untuk setiap unit sampel pada semua penggal jalan diperoleh nilai diatas 2 (q) atau $D V>2$ lebih dari 1, sehingga perlu dihitung nilai $m$ untuk memastikan jumlah maksimum jenis kerusakan lebih besar daripada jumlah kerusakan eksisting di setiap penggal jalannya. Hal ini dilakukan dengan cara mengurutkan nilai $D V$ dari yang terbesar hingga yang terkecil. Kemudian dihitung nilai $\mathrm{m}$ dari nilai $H D V$ (nilai pengurang terbesar) dengan Persamaan 6. Contoh perhitungan nilai $m$ berdasarkan hasil perhitungan pada Tabel 3 sampai dengan Tabel 6 ditampilkan pada Tabel 7.

Tabel 7. Perhitungan Nilai Allowable Maximum Deduct Value (m)

\begin{tabular}{ccccc}
\hline No. & Stasioning & $\begin{array}{c}\text { Nilai DV Terbesar } \\
\left(\mathbf{H D V}_{\mathbf{i}}\right)\end{array}$ & $\begin{array}{c}\text { Nilai Allowable Maximum Deduct Value } \\
(\boldsymbol{m})\end{array}$ & Total $\boldsymbol{q}$ \\
\hline \hline 1. & $0+150 \mathrm{~s} / \mathrm{d}$ 0+200 & 28 & $m=1+(9 / 98)(100-28)=7,61$ & 5 \\
2. & $1+350 \mathrm{~s} / \mathrm{d} 1+400$ & 64 & $m=1+(9 / 98)(100-64)=4,31$ & 5 \\
3. & $2+450 \mathrm{~s} / \mathrm{d} 2+500$ & 21 & $m=1+(9 / 98)(100-21)=8,26$ & 6 \\
4. & $3+250 \mathrm{~s} / \mathrm{d} 3+300$ & 19 & $m=1+(9 / 98)(100-19)=8,44$ & 5 \\
\hline
\end{tabular}

\subsection{Menghitung Nilai Total Deduct Value (TDP) dan Corrected Deduct Value (CDV)}

Untuk mendapatkan nilai $T D V$ dan $C D V$ dilakukan dengan menggunakan data hasil perhitungan pada Tabel 3 sampai dengan 6 dengan langkah-langkah sebagai berikut:

a. Menentukan jumlah $D V$ yang akan dipergunakan untuk menentukan nilai $C D V$. Pada Tabel 7 diperoleh hasil pada Sta. 0+150 s/d 0+200 diperoleh nilai $D V$ sebanyak $5 D V$, yaitu 28, 21, 11,3 dan 1, sedangkan nilai $m$ diperoleh sebesar 7,61, sehingga seluruh nilai yang diperoleh pada unit sampel tersebut akan dipergunakan dalam perhitungan. Pada Sta. 1+350 s/d 1+400 diperoleh nilai $D V$ sebanyak $5 D V$, yaitu $64,28,13,3$, dan 2 , sedangkan nilai $m$ diperoleh sebesar 4,31, berarti 4 nilai DV terbesar nilai 64, 28, 13, dan 3 akan dipergunakan dalam perhitungan, sedangkan nilai $D V$ kelima yaitu nilai 2 akan dikalikan dengan nilai sisa $m$, yaitu 0,31 sebagai angka koreksi, sehingga nilai $D V$ kelima diperoleh sebesar 0,62 (hasil perkalian nilai 2 dengan 0,31 ).

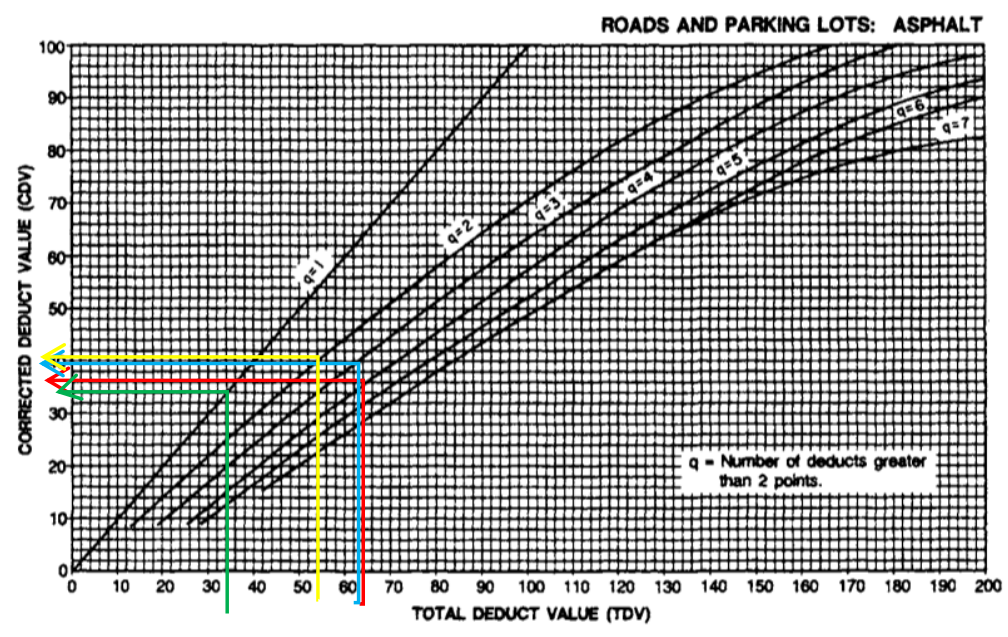

Gambar 7. Penentuan Nilai $C D V$ Pada Unit Sampel Sta. 0+150 s/d 0+200

b. Menentukan $T D V$ untuk setiap unit sampel dengan menjumlahkan seluruh $D V$. Kemudian perhitungan dilakukan secara iterasi dengan cara mengubah setiap nilai yang lebih dari 2 menjadi nilai 2 pada setiap baris, sehingga membentuk matrik segitiga dengan nilai akhir setiap baris 2, kemudian masing-masing baris dijumlahkan untuk mendapatkan nilai $T D V$ 
yang akan dikorelasikan dengan $C D V$ melalui grafik seperti Gambar 3. Cara mendapatkan nilai $C D V$ adalah dengan menarik garis secara vertikal keatas dari setiap nilai $T D V$ dihubungkan ke kurva $q$ (jumlah nilai pengurang) sesuai posisi baris $T D V$ dalam perhitungan iterasi. Berikutnya dari perpotongan garis ke kurva $q$ dilanjutkan penarikan garis secara horisontal kesisi kanan untuk mendapatkan nilai $C D V$. Langkah penggambaran grafik ini dilakukan sebanyak jumlah nilai $q$ yang diperoleh dalam perhitungan iterasi. Contoh perhitungan iterasi untuk unit sampel pada Sta. $0+150$ s/d 0+200 disajikan pada Tabel 8, dan plotting grafik hubungan $T D V$ dan $C D V$ ditampilkan pada Gambar 7.

Tabel 8. Perhitungan TDP dan CDV Pada Unit Sampel Sta. 0+150 s/d 0+200

\begin{tabular}{ccccccccc}
\hline Iterasi & \multicolumn{9}{c}{ Deduct Value } & Total $\boldsymbol{D} \boldsymbol{V}$ & $\boldsymbol{q}$ & $\boldsymbol{C D} \boldsymbol{V}$ \\
\hline \hline$\# 1$ & 28 & 21 & 11 & 3 & 1 & 64 & 4 & 36 \\
$\# 2$ & 28 & 21 & 11 & 2 & 1 & 63 & 3 & 39,5 \\
$\# 3$ & 28 & 21 & 2 & 2 & 1 & 54 & 2 & 40.5 \\
$\# 4$ & 28 & 2 & 2 & 2 & 1 & 35 & 1 & 34 \\
\hline
\end{tabular}

Selanjutnya contoh perhitungan unit sampel pada Sta. $1+350$ s/d 1+400, Sta. $2+450$ s/d 2+500, dan Sta. 3+250 s/d 3+300, ditampilkan pada Tabel 9 sampai dengan Tabel 11.

Tabel 9. Perhitungan TDP dan CDV Pada Unit Sampel Sta. 1+350 s/d 1+400

\begin{tabular}{ccccccccc}
\hline Iterasi & \multicolumn{9}{c}{ Deduct Value } & & Total DV & $\boldsymbol{q}$ & $\boldsymbol{C D V}$ \\
\hline \hline$\# 1$ & 64 & 28 & 13 & 3 & 0,62 & 108,62 & 4 & 63 \\
$\# 2$ & 64 & 28 & 13 & 2 & 0,62 & 107,62 & 3 & 67,5 \\
$\# 3$ & 64 & 28 & 2 & 2 & 0,62 & 96,62 & 2 & 68 \\
$\# 4$ & 64 & 2 & 2 & 2 & 0,62 & 70,62 & 1 & 70.5 \\
\hline
\end{tabular}

Tabel 10. Perhitungan TDP dan CDV Pada Unit Sampel Sta. 2+450 s/d 2+500

\begin{tabular}{cccccccccc}
\hline Iterasi & \multicolumn{1}{c}{ Deduct Value } & \multicolumn{3}{c}{ Total $\boldsymbol{D V}$} & $\boldsymbol{q}$ & $\boldsymbol{C D V}$ \\
\hline \hline$\# 1$ & 21 & 20 & 5 & 5 & 2 & 1 & 54 & 4 & 29 \\
$\# 2$ & 21 & 20 & 5 & 2 & 2 & 1 & 51 & 3 & 32 \\
$\# 3$ & 21 & 20 & 2 & 2 & 2 & 1 & 48 & 2 & 36 \\
$\# 4$ & 21 & 2 & 2 & 2 & 2 & 1 & 30 & 1 & 30 \\
\hline
\end{tabular}

Tabel 11. Perhitungan TDP dan CDV Pada Unit Sampel Sta. 3+250 s/d 3+300

\begin{tabular}{ccccccccc}
\hline Iterasi & \multicolumn{9}{c}{ Deduct Value } & Total $\boldsymbol{D V}$ & $\boldsymbol{q}$ & $\boldsymbol{C D V}$ \\
\hline \hline$\# 1$ & 19 & 6 & 4 & 4 & 4 & 37 & 5 & 15 \\
$\# 2$ & 19 & 6 & 4 & 4 & 2 & 35 & 4 & 16 \\
$\# 3$ & 19 & 6 & 4 & 2 & 1 & 32 & 3 & 18 \\
$\# 4$ & 19 & 6 & 2 & 2 & 1 & 30 & 22 \\
$\# 5$ & 19 & 2 & 2 & 2 & 1 & 26 & 1 \\
\hline
\end{tabular}

\subsection{Menentukan Nilai Pavement Conditition Index (PCI)}

Berdasarkan perhitungan nilai $C D V$ masing-masing unit sampel diperoleh nilai $C D V$ maksimum atau terbesar yang dipergunakan untuk menghitung nilai PCI. Dengan Persamaan 7 maka dapat di hitung nilai PCI unit sampel pada Sta. 0+150 s/d 0+200, Sta. 1+350 s/d 1+400, Sta. 2+450 s/d $2+500$, dan Sta. 3+250 s/d 3+300, dan penilaian kriteria kondisinya berdsarkan Shahin (2005). Hasil perhitungan untuk 4 contoh unit sampel tersebuit disajikan pada Tabel 12. Hasil penilaian PCI masing-masing unit sampel seluruh unit sampel tinjauan disajikan secara grafis seperti ditampilkan pada Gambar 8. 
Tabel 12. Hasil Perhitungan Nilai PCI Untuk Unit Sampel Contoh Keriteria Kondisi Jalan

\begin{tabular}{ccccc}
\hline Sampel No. & Stasioning & $\boldsymbol{C D}$ V Maks & PCI Unit Sampel & Keterangan \\
\hline \hline 2 & $0+150$ s/d 0+200 & 40.5 & 59,5 & Baik (Good) \\
14 & $1+350$ s/d 1+400 & 70.5 & 29,5 & Jelek (Poor) \\
25 & $2+450$ s/d 2+500 & 36 & 64 & Baik (Good) \\
33 & $3+250$ s/d 3+300 & 26 & 74 & Sangat Baik (Very Good) \\
\hline
\end{tabular}

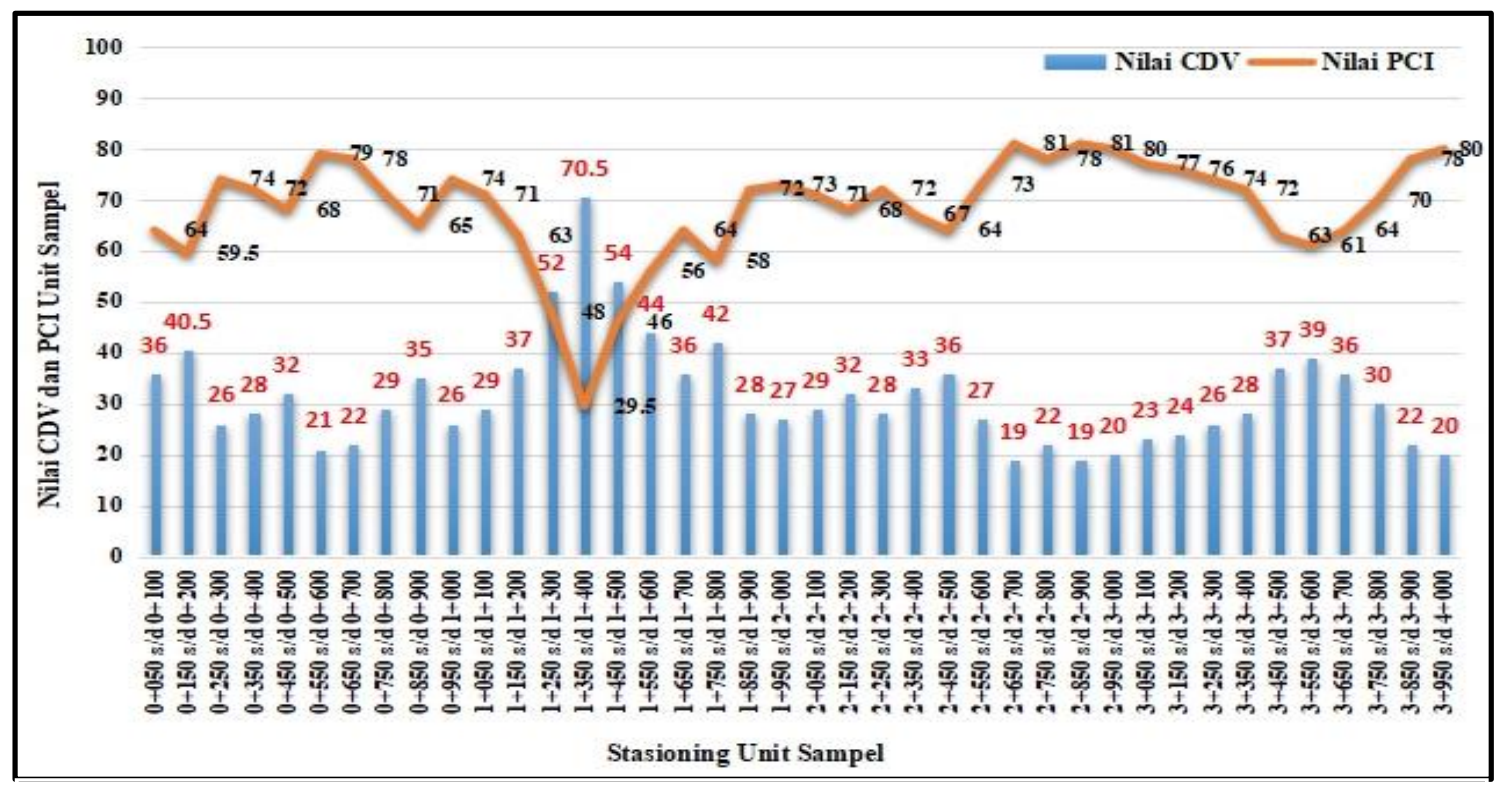

Gambar 8. Grafik Nilai CDV dan PCI Masing-Masing Unit Sampel Jalan

Selanjutnya dengan menggunakan Persamaan 8, dapat dihitung nilai PCI rata-rata dari keseluruhan unit sampel yaitu diperoleh nilai PCI sebesar $\mathbf{7 1}$ dengan kriteria dari ruas Jalan Gunung Selatan berdasarkan Shahin (2005) adalah Sangat Baik (Very Good).

\section{Kesimpulan}

Berdasarkan analisis hasil pemeriksaan kondisi Jalan Gunung Selatan dengan metode $P C I$ (Performance Condition Index) dapat disimpulkan sebagai berikut:

1. Jenis kerusakan yang ditemukan pada ruas jalan yang ditinjau antara lain yaitu: retak kulit buaya (alligator crack), kegemukan (bleeding), retak kotak-kotak (block cracking), keriting (corrugation), amblas (depression), retak samping jalan (edge cracking), retak memanjang/melintang (longitudinal/transverse cracking), tambalan (patching and utility cut patching), lubang (pothole), dan pelepasan butir (weathering/raveling).

2. Hasil penilaian kerusakan jalan secara rata-rata menghasilkan nilai sangat baik (very good) yaitu dengan nilai PCI $=71$, tetapi terdapat satu hasil pengamatan yang memberikan nilai buruk (poor) yaitu unit sampel pada Sta. $1+350$ s/d 1+400 dengan nilai PCI $=29,5$. Hal ini terjadi, karena kondisi lapangan pada saat pengamatan mengalami kerusakan dan sedang dalam perbaikan.

3. Shahin (2005) menyebutkan bahwa pengambilan unit sampel secara acak dalam metode PCI ini mengandung kelemahan, karena bisa saja unit sampel yang terpilih adalah unit sampel dalam kondisi baik dan bisa saja terdapat unit sampel dalam kondisi buruk tidak terpilih dalam peninjauan. Untuk penelitian selnajutnya perlu memasukkan unit sampel tambahan yang tidak terpilih dalam sampel acak dalam peninjauan yang jika tampak secara visual kondisi jalan tersebut mengalami kerusakan yang signifikan dalam penilaian kondisi jalan secara keseluruhan. 


\section{Daftar Pustaka}

Badan Pusat Statistik Kota Tarakan, 2019. Tarakan Dalam Angka Tahun 2019, Badan Pusat Statistik Kota Tarakan, Tarakan

Djalante, S, 2011. Evaluasi Kondisi dan Kerusakan Perkerasan Lentur di Beberapa Ruas Jalan Kota Kendari, Jurnal MEKTEK Universitas Tadulako Palu, Vol. 13 No. 01 Tahun Januari 2011, hal 01-15, ISSN: 1411-0954.

Mubarak, H, 2016. Analisa Tingkat Kerusakan Perkerasan Jalan Dengan Metode Pavement Condition Index (PCI) Studi Kasus: Jalan Soekarno Hatta Sta. 11+150 s.d 12+150, Jurnal SAINTIS Universitas Islam Riau, Vol. 16 No. 01 Tahun April 2016, hal 94-109, ISSN: 1410-7783.

Nawir, D., dan Mansur, A. Z., 2017. Rancangan Perkerasan Jalan, Penerbit Rinra Publishing, Makassar, ISBN: 978-602-18440-5-2.

Shahin, M. Y, 2005. Pavement Management for Airports, Roads, and Parking Lots, Springer Publisher, ISBN-13: 978-0387-23464-9.

Sukirman, S., 1999. Perkerasan Lentur Jalan Raya, Penerbit Nova, Bandung, ISBN: 979-95847-1$\mathrm{x}$.

Widianto, B.W., 2017. Pavement Condition Index (PCI) Runway Bandara Halim Perdanakusuma Jakarta, Jurnal REKA RACANA Jurusan Teknik Sipil Institut Teknologi Nasional Bandung, Vol. 3 No. 01 Tahun Maret 2017, hal 01-13, ISSN: 2477-2569.

Direktorat Jenderal Bina Marga Departemen Pekerjaan Umum, 1983. Manual Pemeliharaan Jalan Nomor: 03/MN/B/1983, Direktorat Jenderal Bina Marga Departemen Pekerjaan Umum, Jakarta 
